\title{
Hypovitaminosis D causes impaired glycemic control in type 2 diabetic patients
}

\author{
Authors: Quratulain Yousuf, ${ }^{A}$ Athesham Zafar, ${ }^{B}$ Kamrudeen Mohammed ${ }^{C}$ and Nauman Jadoon ${ }^{A}$
}

\section{Aims}

To determine the frequency of Vitamin D deficiency and its effect on glycaemic control in patients with type 2 diabetes mellitus.

\section{Methods}

Study design: Cross-sectional study.

Setting: The study was conducted in the Outpatient Department of Medicine, Liaquat National Hospital, Karachi, Pakistan.

Duration of the study: 6 months from June 2015 to December 2015.

Sample size: The sample size was 191 patients, as calculated using World Health Organization software for sample size calculation by using:

$>$ proportion of vitamin D deficiency in type 2 diabetic patients $=$ $58.34 \%$

$>$ margin of error $(\mathrm{d})=7 \%$

$>$ confidence interval $=95 \%$.

Sampling technique: Non-probability consecutive sampling. A total of 191 patients were included in the study. After taking informed consent, blood samples for the assessment of Vitamin D levels were obtained from the patients fulfilling inclusion criteria of the study. Confidentiality of their information was maintained.

\section{Results}

Patients with type 2 diabetes mellitus were significantly vitamin D deficient. Vitamin D deficiency was found to be $69.1 \%$ in patients with type 2 diabetes mellitus. Descriptive statistics of $\mathrm{HbA} 1 \mathrm{c}$ were calculated and showed that $98(62.4 \%)$ patients who had $\mathrm{HbA1c}<8 \%$ were found to be vitamin D deficient while 34 (100\%) patients with $\mathrm{HbA1}>>8 \%$ had vitamin $\mathrm{D}$ deficiency.

Further studies are required for the development of strategies for the supplementation of vitamin D in type 2 diabetic patients for better glycaemic control along with standard treatment.

\section{Conclusion}

Our study found a significantly high frequency of Vitamin D deficiency in patients with type 2 diabetes mellitus. In view of this,

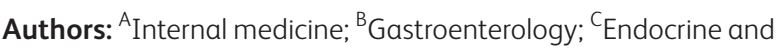
diabetes, Hull Royal Infirmary, Hull, UK

\begin{tabular}{|c|c|c|c|c|c|c|}
\hline \multirow{6}{*}{ HbA1c group } & \multirow[b]{3}{*}{$<8$} & \multirow[b]{3}{*}{$n$} & \multicolumn{2}{|c|}{$\begin{array}{l}\text { Vitamin D } \\
\text { deficiency }\end{array}$} & \multirow[t]{2}{*}{ Total } & \multirow[t]{5}{*}{$\mathrm{p}$ value } \\
\hline & & & Yes & No & & \\
\hline & & & 98 & 59 & 157 & \\
\hline & & $\%$ & 62.4 & 37.6 & 100.0 & \\
\hline & $>8$ & $\mathrm{n}$ & 34 & 0 & 34 & \\
\hline & & $\%$ & 100.0 & 0.0 & 100.0 & 0.000 \\
\hline Total & & & 132 & 59 & 191 & \\
\hline
\end{tabular}

Chi-square test was applied. $p$ value $\leq 0.05$ considered as significant at 0.05 level.

we recommend early replacement of vitamin $D$ in patients with type 2 diabetes mellitus along with the specific therapy to improve the outcome; this may alter the natural history of this disease.

\section{Conflict of interest statement}

No potential conflict of interest. 